\title{
Corpus
}

Archivos virtuales de la alteridad americana

Vol 3, No 2 | 2013

Julio / Diciembre 2013

\section{Las visitas de los tenientes de naturales a los partidos de pueblos de indios de la gobernación del Tucumán. (1606-1607)}

The Visits by "tenientes de naturales" to the "partidos de pueblos de indios" in the Governorate of Tucumán. (1606-1607)

\section{Leticia Daniela Carmignani}

\section{OpenEdition}

\section{Journals}

Édition électronique

URL : https://journals.openedition.org/corpusarchivos/548

DOI : $10.4000 /$ corpusarchivos.548

ISSN : 1853-8037

Éditeur

Diego Escolar

\section{Référence électronique}

Leticia Daniela Carmignani, «Las visitas de los tenientes de naturales a los partidos de pueblos de indios de la gobernación del Tucumán. (1606-1607)», Corpus [En línea], Vol 3, No 2 | 2013, Publicado el 20 décembre 2013, consultado el 28 juin 2022. URL: http://journals.openedition.org/corpusarchivos/548 ; DOI: https://doi.org/10.4000/corpusarchivos.548

Ce document a été généré automatiquement le 29 septembre 2020.

Licencia Creative Commons: Atribución-NoComercial 2.5 Argentina (CC BY-NC 2.5 AR) 


\section{Las visitas de los tenientes de naturales a los partidos de pueblos de indios de la gobernación del Tucumán. (1606-1607)}

The Visits by "tenientes de naturales" to the "partidos de pueblos de indios" in the Governorate of Tucumán. (1606-1607)

\section{Leticia Daniela Carmignani}

\section{NOTE DE L'ÉDITEUR}

Fecha de recepción del original: 10/09/2013

Fecha de aceptación para publicación: 01/11/2013

El documento a que se refiere este artículo se encuentra como Documento Anexo en formato pdf en esta misma página, al final del texto.

\section{Presentación}

Entre 1606 y 1607 al menos seis tenientes de naturales nombrados por el gobernador del Tucumán Alonso de Ribera, recorrían y visitaban pueblos de indios pertenecientes a las jurisdicciones de las ciudades de Santiago del Estero -cabecera de la gobernación-, La Rioja, Córdoba y San Miguel de Tucumán. Otros tenientes habían sido destinados a visitar las jurisdicciones de Salta, Jujuy, Esteco y Madrid de las Juntas, sin embargo, éstos no pudieron llevar a cabo su tarea por haber llegado disposición de la Audiencia de Charcas de detener las visitas. 
2 Los tenientes o jueces de naturales tenían la orden de ejecutar la legislación vigente -las Ordenanzas de 1576 del gobernador Gonzalo de Abreu ${ }^{1-}$ respondiendo a la recurrentemente denunciada situación de abusos y excesos que estaban padeciendo los indios de encomienda de la región bajo el sistema de servicios personales.

3 Podemos conocer las visitas y el accionar de los tenientes gracias los informes que realizaron y que son incorporados en las cartas del gobernador Ribera dirigidas al Rey, cuyos originales se encuentran en el Archivo General de Indias-Sevilla (AGI), y por ellas sabemos también que la Audiencia de Charcas dio la contraorden para que se dejaran de realizar estas visitas y se anulara el accionar de los tenientes a poco tiempo de haberse iniciado.

4 Dichos informes, detallados por jurisdicción fueron incorporados en dos de las cartas del gobernador Alonso de Ribera al Rey, en 1607 y en 1608. Por lo tanto, los informes aquí ofrecidos se ubican y pertenecen a dicho conjunto documental.

5 Las cartas de gobernadores al rey eran informaciones que los gobernadores redactaban periódicamente sobre el estado general de la jurisdicción que tenían a su cargo, prestando atención también a asuntos especiales que iban surgiendo. El objetivo era dar cuenta al rey de la situación regional, dar a conocer los logros de la gestión o los resultados de determinadas políticas o simplemente exponer los problemas o dificultades existentes. A su vez, podía buscar la aprobación real de un proyecto o decisión que se quería realizar o se estaba realizando. El envío al rey de las cartas aquí presentadas se realiza luego de la suspensión por parte de la Audiencia de las visitas de los tenientes nombrados por el gobernador y este funcionario quien envía al rey el resultado de las visitas como modo de exponer la situación de las sociedades indígenas y el remedio que estaba significando su gestión para conservación de los naturales y “descargo de la real conciencia”.

\section{Cartas similares, información diferenciada.}

6 Hemos recuperado y comparado dos documentos conocidos y utilizados por los investigadores que se han dedicado a problematizar el servicio personal en el Tucumán en el marco de las Ordenanzas de Abreu y de los cuales contamos con dos transcripciones previas, una editada de manera incompleta por Ricardo Rodríguez Molas en 1985 y otra transcripción inédita ubicada en el Fondo Documental Monseñor Pablo Cabrera de la Biblioteca de la Facultad de Filosofía y Humanidades de la Universidad Nacional de Córdoba. Se trata de dos cartas escritas por el Gobernador del Tucumán Alonso de Ribera (1606-1611) al Rey que, por su estructura inicial, parecían ser iguales aunque de fechas diferentes.

7 Para esclarecer las diferencias entre ambas copias de un documento que a simple vista parecía ser el mismo y a partir de un trabajo previo de Isabel Castro (2008), recurrimos a los originales del Archivo General de Indias que pueden ser consultados de manera pública a través del Portal de Archivos Españoles (PARES) ${ }^{2}$, con el objetivo de contrastar las transcripciones y comprobar si se trataba del mismo documento o de dos documentos diferentes.

La primera transcripción realizada a principio de Siglo XX por Gaspar García Viñas hoy se encuentra mecanografiada en Colección que lleva su nombre en la Sala del Tesoro de la Biblioteca de la Nación Argentina (CGGV no 3967) y es la más conocida y citada por los investigadores, y fue editada casi completa por Ricardo Rodríguez Molas (1985, pp. 
115-122). La segunda carta, inédita aún, fue también transcripta a principios del siglo XX, más específicamente en 1919 por Santiago Montero en Sevilla y dicha transcripción mecanografiada se halla en el Fondo Documental Monseñor Pablo Cabrera, en la Biblioteca de la Facultad de Filosofía y Humanidades de la Universidad Nacional de Córdoba (FDPC n¹2771).

Los dos documentos originales consultados están disponibles en el citado Portal digital PARES, digitalizados dentro de la serie "Cartas de Gobernadores" bajo la signatura CHARCAS,26,R.8,N.46 ubicándose con una única signatura ambas cartas, rotuladas con una misma fecha de creación el 11 de febrero de 1608 .

Sin embargo, el análisis de la estructura del documento digitalizado nos permitió identificar que bajo una misma signatura se encuentran cuatro documentos distribuidos en cuatro bloques:

- el primero corresponde a una carta al Rey del gobernador del Tucumán Alonso Ribera con la fecha del 11 de febrero de 1608 y consta de 8 folios rectos y versos.

- el segundo bloque corresponde a otra carta del mismo denominada: "Relación de los excesos que se cometen contra los naturales de la provincia del Tucumán para el rey", ésta fechada el 14 de mayo de 1607 y consta de 14 folios rectos y vueltos.

- el tercer bloque presenta el "parecer del Padre Baltasar de Navarro de la orden de San Francisco sobre si se ponían tenientes en los pueblos de indios" con dos folios rectos y dos vueltos.

- el último corresponde a la "Relación del padre Juan Jiménez", con dos folios rectos y dos vueltos

11 De estos cuatro bloques, recuperamos específicamente los dos primeros por corresponder a los originales de las dos cartas que contienen los informes de las visita y son los que deseamos contrastar y presentar su transcripción como aporte. En tanto los otros dos bloques corresponden a documentos, aunque muy valiosos, diferentes a las cartas y a los informes de los tenientes de naturales que fueron incorporados a las cartas de manera anexa por el gobernador tratándose de "pareceres" o informaciones realizadas por religiosos que ya han sido publicados en parte. ${ }^{3}$

12 Así, el primer bloque de imágenes corresponde a la carta original de la transcripción ubicada en la colección Gaspar García Viñas y editada por Rodríguez Molas, escrita por el gobernador Ribera el 11 de febrero de 1608. El segundo bloque de imágenes, más extenso que el primero, era el original de la carta del 14 de mayo de 1607, cuya copia se ubica en el FDPC.

\section{Transcripción paleográfica}

Dichos documentos fueron escritos por Alonso de Ribera, en soporte papel, con un tipo de letra semejante o que tiende a ser "procesal" y se caracteriza por no regirse por preceptos caligráficos ni reglas de ortografía y por una separación irregular en las palabras a la que se suma una profusión de los rasgos inútiles de algunas letras (Tanodi, 1994). Ambos documentos se encuentran en buen estado y completos en formato digital. ${ }^{4}$ No representan manchas ni roturas de mayor consideración que impidan la lectura de algún segmento del texto. No poseen foliación propia, por lo que utilizamos la foliación propuesta por PARES. 
"Normas para la Transcripción de Documentos Históricos Panamericanos" propuesta en 1961 en Washington (Tanodi, 2000), de los dos documentos originales de 1607 y 1608 ubicados en el Archivo General de Indias.

transcripciones de los documentos permitieron contrastar la información presente en cada una de las cartas y comprobar que, a pesar de que comienzan brindando los mismos datos, no son "copias" entre sí, ya que ambas presentan información particular.

Además, la alteración en el orden de uno de los folios del documento de 1607 en el portal digital del Archivo General de Indias, se pudo resolver gracias a la existencia de la copia mecanografiada de principio de siglo XX en la biblioteca de la Facultad de Filosofía de Córdoba, dando lugar a la transcripción correcta de la carta. A su vez, pudimos constatar que la transcripción édita de Rodríguez Molas -tomada del documento de la CGGV- del documento de 1608 había omitido algunos párrafos del documento original del AGI.

Una vez realizadas las dos transcripciones de los originales y al contar con las dos mecanografiadas de principio de siglo XX (que fueron tipeadas nuevamente), realizamos un análisis comparativo siguiendo la estructura de los párrafos del documento que permitió, en una primera instancia realizar una reconstrucción de los documentos originales y, en una segunda, analizar las diferencias elementales en la información brindada por cada uno de ellos.

\section{Visitas realizadas a los indios por jurisdicción y por partidos}

18 Ambas cartas, en 1607 y en 1608, son dirigidas por Alonso de Ribera, Gobernador de Tucumán, al Rey o al Consejo de Indias. Tienen una estructura similar cuyos objetivos próximos son, por una parte informar al rey sobre los excesos y agravios que sufrían las sociedades indígenas de dicha gobernación por parte de encomenderos y pobleros en el marco de la explotación por medio del sistema de encomiendas de servicio personal. Y por otra parte y principalmente, tenían el objetivo de exponer al Rey lo beneficiosa que había resultado durante el tiempo que pudo llevarse a cabo, la medida de nombramiento de tenientes de naturales y la visita de la tierra que estos habían realizado desagraviando a los indios, y que sin embargo había sido suspendida por la Audiencia de Charcas.

19 Como hemos trabajado en profundidad gracias al cruce de diferentes documentos (Carmignani, 2013), consideramos que la política del gobernador había consistido en el nombramiento entre 1606 y 1607 de lugartenientes de gobernador con órdenes de visitar la tierra y aplicar las ordenanzas vigentes del gobernador Gonzalo de Abreu (1576), desagraviando a los indios y castigando a quienes las incumplieran. Especialmente tenían que velar por el buen trato hacia los indios, el cumplimiento de las tasas de tiempo de trabajo y la condición de indios reservados para los casos que la ordenanza así lo prescribe.

Para la realización de estas visitas, el gobernador, además de otorgar a cada teniente vara de justicia, le señala un distrito determinado, dependiente de la jurisdicción de las ciudades denominándolo "partido de pueblo de indios" o solamente "partido" que correspondía, e incluía, a los territorios en los que se asentaban los pueblos de indios de encomienda y las estancias españolas que utilizaban la mano de obra de esos indios, por tiempo de un año.

Corpus, Vol 3, No 2 | 2013 
21 En este contexto, el gobernador ofrece al Rey los resultados de las visitas ${ }^{5}$ de los tenientes y describe las diferentes jurisdicciones.

En primer lugar, en las dos cartas se informa de manera general sobre la situación de agravios en los términos de la ciudad de Santiago del Estero, comprendiendo sus tres partidos: del Río Dulce; del Río Salado y de la Sierra. En el caso de la jurisdicción de Santiago, la información de ambas cartas es igual y por lo tanto, es lo mismo consultar cualquiera de sus originales o transcripciones.

23 A continuación ambos documentos pasan a describir los excesos de la jurisdicción de La Rioja, comenzando con el Partido del Valle de Londres; en este apartado, enumeran y describen procesos judiciales que habían sido realizados por el teniente de naturales contra encomenderos y pobleros indicando los pueblos de indios en donde habían tenido lugar los delitos. La carta de 1608 contiene 7 de estos, mientras que la carta de 1607 además de esos incluye otro proceso judicial (realizado Contra Gaspar Domínguez poblero de Decagasta) e incorpora otras causas del proceso realizado contra Pedro Tello de Sotomayor (vecino de la dicha ciudad de la Rioja). Esta última información se encuentra ausente en la carta de 1608, por lo que resulta importante consultar el documento de 1607 para completar la información sobre esta jurisdicción.

Se sintetizan las coincidencias y diferencias de ambos documentos en el siguiente cuadro

\begin{tabular}{|c|c|c|}
\hline & $\begin{array}{l}\text { DOCUMENTO } 1 \\
14 \text { de mayo de } 1607 \\
\text { (AGI.CHARCAS,26,R.8,N.46) } \\
\text { Bloque } 2.14 \text { fs. } \\
\text { PARTIDOS / ENCOMIENDAS / } \\
\text { CAUSAS }\end{array}$ & $\begin{array}{l}\text { DOCUMENTO } 2 \\
11 \text { de febrero de } 1608 \\
\text { (AGI.CHARCAS,26,R.8,N.46) } \\
\text { Bloque 1. } 8 \text { Fs. } \\
\text { PARTIDOS/ENCOMIENDAS /CAUSAS }\end{array}$ \\
\hline \multirow[t]{2}{*}{$\begin{array}{l}\text { SANTIAGO } \\
\text { DEL ESTERO }\end{array}$} & $\begin{array}{l}\text { PARTIDO DEL RIOS DULCE } \\
\text { PARTIDO DEL RÍO SALADO PARTIDO } \\
\text { DE LA SIERRA } \\
\text { La información de los tenientes se } \\
\text { presenta de manera general y } \\
\text { conjunta para los tres partidos. }\end{array}$ & $\begin{array}{l}\text { PARTIDO DEL RIOS DULCE } \\
\text { PARTIDO DEL RÍO SALADO PARTIDO DE } \\
\text { LA SIERRA } \\
\text { La información de los tenientes se } \\
\text { presenta de manera general y conjunta } \\
\text { para los tres partidos. }\end{array}$ \\
\hline & \multicolumn{2}{|c|}{ Los dos documentos coinciden en la información. } \\
\hline LA RIOJA & $\begin{array}{l}\text { VALLE DE LONDRES } \\
\text { - Machigasta (Menor de Fancisco } \\
\text { Robledo) } \\
\text { - Juctava } \\
\text { - Paccipa } \\
\text { - Sabuil } \\
\text { - Contra Pedro Tello de Sotomayor } \\
\text { vezino de la dicha çiudad de La } \\
\text { Rioxa (12 acusaciones) } \\
\text { - Decagasta } \\
\text { - Olcagasta }\end{array}$ & $\begin{array}{l}\text { VALLE DE LONDRES } \\
\text { - Machigasta (Menor de Fancisco } \\
\text { Robledo) } \\
\text { - Juctava } \\
\text { - Paccipa } \\
\text { - Sabuil } \\
\text { - Contra Pedro Tello de Sotomayor } \\
\text { vezino de la dicha çiudad de La Rioxa } \\
\text { (INCOMPLETA } 2 \text { acusaciones) } \\
\text { - OMITIDA } \\
\text { - Olcagasta }\end{array}$ \\
\hline
\end{tabular}




\begin{tabular}{|c|c|c|}
\hline & $\begin{array}{l}\text { PARTIDO DE FAMATINA } \\
\text {-contra Lázaro indio poblero de } \\
\text { Pedro Díaz (1 acusación) } \\
\text { - OMITIDA } \\
\text { - OMITIDA } \\
\text { - OMITIDA } \\
\text { - OMITIDA } \\
\text { - OMITIDA } \\
\text {-contra Alonso Díaz Caballero vecino } \\
\text { de la ciudad de Córdoba } \\
\text {-contra Francisco Redondo }\end{array}$ & $\begin{array}{l}\text { PARTIDO DE FAMATINA } \\
\text {-contra Lázaro indio poblero de Pedro } \\
\text { Díaz (3 acusaciones) } \\
\text {-contra Juan de Contreras y Juan de } \\
\text { Papua, poblero } \\
\text { - contra Gaspar de Bañuelos, poblero } \\
\text { del encomendero Gonzalo Duarte de } \\
\text { Meneses } \\
\text {-contra Luis Francisco, poblero de } \\
\text { otro pueblo del encomendero Gonzalo } \\
\text { Duarte de Meneses } \\
\text {-contra Diego Bautista poblero del } \\
\text { pueblo de Ampata de Juan Galiano } \\
\text { Sarmiento } \\
\text {-Contra Juan de Arze Poblero del } \\
\text { pueblo de Machigasta de Francisco } \\
\text { Robledo } \\
\text { - contra Alonso Díaz Caballero vecino de } \\
\text { la ciudad de Córdoba } \\
\text {-contra Francisco Redondo }\end{array}$ \\
\hline \multirow[t]{3}{*}{ CóRDOBA } & $\begin{array}{l}\text { PARTIDO DE LOS RÍOS } \\
\text {-Información general }\end{array}$ & $\begin{array}{l}\text { PARTIDO DE LOS RÍOS } \\
\text {-Información general }\end{array}$ \\
\hline & $\begin{array}{l}\text { PARTIDO DE QUILINO } \\
\text {-Información general }\end{array}$ & $\begin{array}{l}\text { PARTIDO DE QUILINO } \\
\text {-Información general }\end{array}$ \\
\hline & $\begin{array}{l}\text { PARTIDO DE SOTO } \\
\text {-Relación general de Teniente } \\
\text { COMPLETA }\end{array}$ & $\begin{array}{l}\text { PARTIDO DE SOTO } \\
\text {-Relación general BREVE RESUMEN } \\
\text { realizada por el Gobernador }\end{array}$ \\
\hline TUCUMAN & OMITIDO & $\begin{array}{l}\text { PARTIDO DE SAN MIGUEL DE } \\
\text { TUCUMÁN } \\
\text { - información general }\end{array}$ \\
\hline
\end{tabular}

Sin embargo, en el apartado siguiente sobre el Partido de Famatina también de la ciudad de la Rioja, mientras la carta de 1608 enumera y explica 8 procesos legales, la de 1607 sólo nombra y refiere brevemente a cuatro causas.

Resumiendo, en el caso de la jurisdicción de La Rioja para reconstruir el universo de pueblos y encomiendas visitados, así como de los procesos iniciados por los tenientes de naturales, se hace necesario consultar ambas cartas, la de 1607 y la de 1608.

En el caso de los partidos de la jurisdicción de la ciudad de Córdoba: del Rio de la Ciudad de Córdoba, de Quilino y de Soto, Alonso de Ribera informa a partir de los escritos recibidos de quienes habían sido sus respectivos tenientes, siendo más completa la información sobre el partido de Quilino. Para el partido de Soto la información proviene directamente de la Relación General realizada por el teniente Francisco de Avellaneda. Gracias al análisis 
comparativo de los documentos pudimos apreciar que en el informe de 1607 se encuentra la relación extensa de letra del teniente, mientras que en el documento de 1608 el gobernador hace referencia a algunos de los asuntos tratados en la dicha relación general. En este sentido el documento inédito de 1607, estaría realizando un aporte importante para las investigaciones futuras sobre el partido de Soto y, en general, gracias al trabajo comparativo podríamos establecer que un estudio específico sobre la jurisdicción de Córdoba debería considerar la carta de 1607 más que la de 1608 cuya información es más breve y resumen de la primera.

Por otra parte, la carta de 1608 incluye la información brindada por el teniente del Partido de la Ciudad de Tucumán, que no había sido incluida en la del año anterior, ya que el mismo gobernador aclara que al momento de su escritura (febrero de 1607) aun no contaba con los informes del teniente.

Finalmente, en el caso de la carta de 1607 también aclara el gobernador que no llegaron las informaciones del teniente que tenía a su cargo las jurisdicciones de Salta, Jujuy, Esteco y Madrid de las Juntas, diciéndonos en 1608 que el dicho teniente no llegó a realizar su visita en tanto durante ese período de tiempo había arribado la orden de suspenderla por parte de la Audiencia de Charcas.

\section{Las visitas de los tenientes como modo de aproximarnos a la coyuntura pre alfariana}

Como adelantábamos, los informes fueron realizados entre 1606 y 1607 por tenientes de naturales mientras visitaban y recorrían, con la orden de ir aplicando las Ordenanzas vigentes del gobernador Abreu, y se encuentran incluidos en dos cartas enviadas al Rey por el gobernador del Tucumán, Alonso de Ribera. Dichas visitas se enmarcan así en un período temprano e inmediatamente anterior a la visita y Ordenanzas realizadas en 1612, por el Oidor de la Audiencia de Charcas Francisco de Alfaro y la riqueza de estos documentos reside en la diferenciación por partido que se efectúa incorporando los informes que habían realizado los tenientes y en la enumeración tanto de los excesos y abusos que se cometían en ellos como de las causas judiciales que se habían iniciado.

Son pocos los estudios sobre las visitas anteriores a la de Alfaro, en tanto de ésta última resultaron las conocidas ordenanzas que son vistas como un elemento legislativo clave de intervención en la región y por lo tanto, los trabajos existentes apuntan a examinar recorridos en esa dirección. Entre ellos, Gastón Doucet (1986) realiza una "génesis" de la "visita de la tierra", analizando el recorrido burocrático, las órdenes e intentos fallidos para la realización de la demorada "visita" de la gobernación del Tucumán, que concretó el Oidor Alfaro en 1611, de la cual resultaron las posteriores ordenanzas.

En este recorrido, Doucet considera a la política de Ribera como un "intento" de visita ya que para él

"hubo en Tucumán otro intento de visita de los naturales por un gobernador. Fue este Alonso de Ribera, quien, habiéndose propuesto 'visitar la tierra', comunicó su intención al licenciado Maldonado de Torres. La respuesta que obtuvo le hizo detener la realización del proyecto: el Presidente le manifestó que 'tendría por acertado' suspendiese la visita, en razón de haber recibido orden del Rey acerca 'de lo que se ha de hacer en esto' [alusión a la cédula de 1605 o a la de marzo del siguiente año], y le anunció que en breve le daría aviso de lo que, en conformidad con lo dispuesto por la Corona, había de ejecutarse. En marzo de 1607 el Gobernador 
informó al Rey que, pese a lo dicho, ninguna comunicación sobre el particular había recibido hasta entonces." (Doucet, 1986, p. 189) concretarse en su totalidad en tanto además de las "visitas" de los tenientes a los partidos, aplicando justicia y haciendo cumplir las Ordenanzas de Abreu, tenía entre sus planes empadronar a todos los indios, reformar dichas ordenanzas y tasar el tributo (Carmignani, 2013), sus cartas al Rey y el nombramiento efectivo de los "tenientes de naturales", permiten sostener que, al menos hasta su suspensión, la visita concretamente se llevó a cabo superando el "intento" e implicó una intervención favorable a las sociedades indígenas (Castro Olañeta, 2008; Carmignani, 2013). Por esta razón es que el gobernador puede incorporar en las cartas al Rey las informaciones que los tenientes realizan en sus efectivos recorrido por los "partidos" correspondientes. En algunos casos puntuales, también incorpora padrones de indios.

$$
\text { visita del Oidor Francisco de Alfaro efectivamente se realizó entre los años } 1611 \text { y 1612, tal }
$$
como el mismo lo expresa:

"Yo e visitado por mi persona toda esta gobernacion haciendo las preguntas que me parecían convenientes para entender el estado de la tierra y cosas que se devian disponer estas preguntas se hicieren a los indios...". ${ }^{6}$

Pero desafortunadamente no contamos con una copia de ésta y sólo conocemos las Ordenanzas que el mismo Oidor elaboró al término de dicha visita y como consecuencia de la situación observada en ella. En tanto estas ordenanzas como cuerpo legal, se realizan para controlar o revertir situaciones existentes de hecho, su análisis permite deducir o imaginar una situación previa y por lo tanto nos puede brindar una aproximación respecto a lo que vio Alfaro en la visita y que sin embargo, al referirse las ordenanzas mayormente a la gobernación en general, dificultan la visualización de situaciones locales o sub regionales. ${ }^{7}$

En otro trabajo, Doucet (1990) indaga si un cuerpo legal, específicamente las "Ordenanzas de Abreu", debe ser visto como creador o, por lo contrario, como regulador del sistema de prácticas vigentes, es decir del sistema de encomiendas de servicio personal -de aprovechamiento directo, por parte de los encomenderos, de la fuerza laboral de los encomendados-. Frente a esta pregunta inicial, sostiene que el sistema de prácticas descripto por las referidas ordenanzas, "debe considerarse, [...] no creado, sino sólo reglamentado por dicho cuerpo legal..." (Doucet, 1990, p.143). ${ }^{8}$ Es en este sentido, y tomando recaudos metodológicos, como analiza las ordenanzas de 1576, que a su vez deben y pueden ser contrastadas en la medida de lo posible con otros documentos.

En este contexto, consideramos que la recuperación de los informes presentados por Ribera -diferenciados por partidos- nos permite conocer las situaciones regionales que, por el corto período de tiempo transcurrido y por la ausencia en éste de sanción de algún cuerpo legal respecto a los indios que pudiera haber cambiado considerablemente la situación, no distarían demasiado de las situaciones observadas por Alfaro en 1612. A la vez, permitirá tener una idea más compleja de las Ordenanzas de Alfaro como cuerpo legal regulador o creador de prácticas vigentes.

38 Además, debemos pensar que, de haber podido los tenientes en algún punto "revertir" la situación de excesos y abusos, sus efectos no deberían haber perdurado más allá de la suspensión de la visita, y que, con el fin de los "castigos", se habría tendido a retomar la situación general de abusos mantenida hasta la visita de Alfaro, al menos. 
39 En términos generales estos informes -ya sea por la carta de 1607 o por la de 1608- han sido analizados en torno a la explotación por medio del servicio personal por, entre otros autores, Rodríguez Molas (1985), Lorandi (1988), Doucet (1986,1990), Palomeque (2000), Castro (2008). Además fueron recuperados para el estudio de casos por, entre otros, Quiroga (2012) sobre la Rioja y Valle de Londres y por Piana (1992), Castro (2006), Carmignani (2013) y González Navarro (2012) para los partidos de Córdoba.

Finalmente, para el análisis de la situación general observada por los tenientes y plasmada en sus informes, tenemos que contemplar que estos funcionarios estaban visitando los partidos con el objetivo principal de aplicar justicia y hacer cumplir las vigentes ordenanzas de Abreu de 1576. Es decir que las situaciones observadas y descriptas por ellos deben ubicarse en ese marco y que dichas ordenanzas, de alguna forma, sirvieron como guía respecto de los asuntos a los que los tenientes atienden.

41 Asimismo, el hecho de que los tenientes utilizaran como guía estas ordenanzas, no garantiza que se les haya prestado atención en igual medida a todos los puntos o asuntos allí contemplados. Por otras cartas del gobernador al Rey, entendemos que de todas las ordenanzas de Abreu que se pudieran estar incumpliendo, las que más le preocupaban eran las referidas a la explotación de la unidad doméstica, en tanto eran las que en mayor parte afectaban la "conservación" y reproducción de los indios. Específicamente parece apuntar al cumplimiento de los tiempos de trabajo y exenciones previstas en las ordenanzas y a castigar los abusos y malos tratamientos.

De todas maneras, aunque el panorama ofrecido por los informes de los tenientes no puede ser visto como una visión completa y acabada de la situación, brinda valiosa información respecto a asuntos puntuales y privilegiados por los tenientes, y probablemente por el gobernador que los había nombrado.

43 Consideramos que el aporte principal de este trabajo ha sido la identificación y transcripción paleográfica de la carta de 1607 como un documento diferente -y por lo tanto capaz de aportar nueva información- de la carta conocida de 1608 de la cual también ofrecemos la transcripción paleográfica, en la que se eliminan omisiones y errores presentes en la versión édita de 1985.

Por otro lado, por medio de un trabajo comparado hemos puesto a la luz las diferencias fundamentales entre los dos documentos originales y las dos trascripciones previas de los mismos. De esta forma ofrecemos referencias de la información contenida en los distintos documentos acerca de cada partido y jurisdicción.

Creemos que nuestra contribución reside en la recuperación de documentos de gran importancia para la historia colonial y la etnohistoria regional, al poner a disposición las trascripciones de los documentos originales del Archivo General de Indias para que puedan servir como fuentes en próximos trabajos de investigación. 


\section{BIBLIOGRAPHIE}

Castro Olañeta, I. (2006). Transformaciones y continuidades de sociedades indígenas en el sistema colonial. El pueblo de indios de Quilino a principios del siglo XVII. Córdoba: Alción Editora.

Castro Olañeta, I. (2008). Sistema de tributación y encomienda en el Tucumán durante la colonia temprana, XXI Jornadas de Historia Económica. Universidad Nacional Tres de Febrero. Caseros, Buenos Aires.

Carmignani, L. (2013). Política colonial y sociedades indígenas en la Gobernación del Tucumán. El gobernador Alonso de Ribera, los Tenientes de Naturales y la elite encomendera durante la vigencia de las Ordenanzas de Abreu. Tesis Inédita. Facultad de Filosofía y Humanidades. Universidad Nacional de Córdoba. Córdoba.

Doucet, G. (1986). Génesis de una 'visita de la tierra': los orígenes de la visita de las gobernaciones de Tucumán y Paraguay por el Licenciado Don Francisco de Alfaro. Revista de Historia del Derecho, 14, Buenos Aires, pp. 123-220.

Doucet, G. (1990). La encomienda de servicio personal en el Tucumán, bajo régimen legal: comentarios a las ordenanzas de Gonzalo de Abreu. en: Levaggi, Abelardo (Coord.), El aborigen y el derecho en el pasado y el presente, (pp.141-244). Buenos Aires: Universidad del Museo Social Argentino.

González Navarro, C. (2012). Pobleros, mayordomos y administradores en el mundo rural cordobés (1580-1650). Surandino Monográfico, segunda sección del Prohal Monográfico, vol. II, no. 2 Buenos Aires. ISSN 1851-90914 [On line]. Disponible: http://www.filo.uba.ar/contenidos/ investigacion/institutos/ravignani/prohal/mono.html

Levillier, R. (1918). Carta del Licenciado D. Francisco de Alfaro, oidor de la Real Audiencia de la Plata a S.M. San Miguel del Tucumán, 23 de Enero de 1612. Correspondencia de la Ciudad de Buenos Aires con los reyes de España II (pp.237-338) Madrid.

Levillier, R. (1920). Ordenanzas dadas por Gonzalo de Abreu para el buen tratamiento de los indios en las provincias del Tucumán y estableciendo reglas para su trabajo en el laboreo de las minas. Santiago del Estero, 10-IV-1576. Gobernación del Tucumán: Papeles de gobernadores en el siglo XVI. Documentos del Archivo de Indias. pp.32-45.

Lorandi, A. M. (1988). El servicio personal como agente de desestructuración del Tucumán colonial, Revista Andina, 6, Cusco. 135-173.

Palomeque, S. (2000). El mundo indígena. Siglos XVI-XVIII. En: Tandeter, Enrique (Dir.), Nueva Historia Argentina, Tomo II: La sociedad colonial. (pp.87-143) Buenos Aires: Sudamericana.

Piana, J. (1992). Los indígenas de Córdoba bajo el régimen colonial 1570-1620, Córdoba.

Quiroga, L. (2012). Las granjerías de la tierra: actores y escenarios del conflicto colonial en el valle de Londres (gobernación del Tucumán, 1607-1611). Surandino Monográfico, segunda sección del Prohal Monográfico, vol.. II, no.. 2 Buenos Aires. ISSN 1851-90914 [On line]. Disponible: http:// www.filo.uba.ar/contenidos/investigacion/institutos/ravignani/prohal/mono.html

Rodríguez Molas, Ricardo. (1985). Los sometidos de la conquista. Argentina, Bolivia, Paraguay. Buenos Aires: CEAL. 
Tanodi, B. (1994). La escritura en Córdoba del Tucumán (1573- 1650). Córdoba: Universidad Nacional de Córdoba.

Tanodi, B. (2000). Documentos históricos. Normas de Transcripción y Publicación. Cuadernos de Historia. Serie Economía y Sociedad. №3. CIFFyH. Córdoba.259-270.

\section{NOTES}

1. Ordenanzas dadas por Gonzalo de Abreu para el buen tratamiento de los indios en las provincias del Tucumán y estableciendo reglas para su trabajo en el laboreo de las minas. Santiago del Estero, 10-IV-1576. (Levillier, 1920).

2. Raíz de unidades de descripción: Archivo General de Indias/Gobierno /Audiencia de Charcas/ Cartas y expedientes de Gobernadores/CARTAS DE GOBERNADORES. (AGI.CHARCAS,26,R.8,N.46)

3. El documento del bloque 4 corresponde al "Parecer del padre juan romero que envía al rey el gobernador de tucumán” 1608. en Colección Gaspar García Viñas., n³887. (En Rodríguez Molas, 1985, p. 115).

4. Debemos aclarar que en la carta de 1607 (correspondiente al bloque 2 del documento) entre los folios 5 y 6 debería ubicarse el que figura como folio 9 (recto y vuelto).

5. No sabemos si los informes de las visitas incorporados están completos o pertenecen a una selección realizada por Ribera sobre los asuntos que le interesa comunicar.

6. Carta del Licenciado D. Francisco de Alfaro, oidor de la Real Audiencia de la Plata a S.M. San Miguel del Tucumán, 23 de Enero de 1612. (Levillier, 1918).

7. En algunas excepciones las Ordenanzas de Alfaro si brindan referencias locales, como "en los llanos de la Rioja" o "en las Sierras de Córdoba".

8. Recordamos además que las Ordenanzas de Abreu fueron el resultado de una "negociación" entre el gobernador y los encomenderos, (Palomeque, 2000) de quienes dependía el cumplimiento de dicha norma, y quienes eran los beneficiados en el sistema vigente de "hecho."

\section{RÉSUMÉS}

Los documentos presentados corresponden a dos cartas del gobernador del Tucumán Alonso de Ribera al Rey, del 14 de mayo de 1607 y del 11 de febrero de 1608, que ofrecen los resultados de las visitas realizadas por los tenientes o jueces de naturales que el gobernador había designado para que visitaran los partidos de las ciudades de Córdoba, La Rioja, Santiago del Estero y Tucumán durante los años 1606 y 1607 con el objetivo de desagraviar a los Indios y aplicar las Ordenanzas vigentes de 1576 del gobernador Gonzalo de Abreu.

The documents presented correspond to two letters from the Governor of Tucumán Alonso de Ribera to the King, of May 14, 1607 and February 11, 1608 which offer the results of the visitas by the tenientes o jueces de naturales to whom the Governor had designated for visiting smaller jurisdictions called partidos de Pueblos de Indios which were responsible to the cities of Córdoba, La Rioja, Santiago del Estero and Tucumán during the years 1606 and 1607 with the aim of making amends to the indigenous population in fulfillment of the ordinances of 1576. 
INDEX

Keywords : Visitas, Governorate of Tucumán, 17th century, Partidos de Pueblos de Indios

Palabras claves : Gobernación de Tucumán, siglo XVI

\section{AUTEUR}

\section{LETICIA DANIELA CARMIGNANI}

Facultad de Filosofía y Humanidades, Universidad Nacional de Córdoba, Argentina Correo electrónico: leticiacarmignani@gmail.com 